\title{
Agonistic Antibodies Reveal the Function of GPR56 in Human Glioma U87-MG Cells
}

\author{
Shigeyuki Ohta, ${ }^{a}$ Sayaka Sakaguchi, ${ }^{a}$ Yuki Kobayashi, ${ }^{a}$ Norikazu Mizuno, ${ }^{* a, b}$ Kenji Tago, ${ }^{a, c}$ and \\ Hiroshi Itoh*,a \\ ${ }^{a}$ Department of Biomedical Science, Graduate School of Biological Sciences, Nara Institute of Science and \\ Technolog; 8916-5 Takayama, Ikoma, Nara 630-0192, Japan: ${ }^{b}$ Faculty of Pharmaceutical Science, Aomori \\ University; 2-3-1 Kohbata, Aomori 030-0943, Japan: and ${ }^{c}$ Department of Biochemistry, School of Medicine, Jichi \\ Medical University; Shimotsuke, Tochigi 329-0498, Japan.
}

Received October 31, 2014; accepted January 27, 2015

GPR56 is a member of the adhesion G protein-coupled receptor (GPCR) and is highly expressed in parts of tumor cells. The involvement of GPR56 in tumorigenesis has been reported. We generated agonistic monoclonal antibodies against human GPR56 and analyzed the action and signaling pathway of GPR56. The antibodies inhibited cell migration through the Gq and Rho pathway in human glioma U87-MG cells. Coimmunoprecipitation analysis indicated that the interaction between the GPR56 extracellular domain and transmembrane domain was potentiated by agonistic antibodies. These results demonstrated that functional antibodies are invaluable tools for GPCR research and should open a new avenue for therapeutic treatment of tumors.

Key words G protein signal; agonistic antibody; adhesion G protein-coupled receptor (GPCR); glioma cell migration

G protein-coupled receptor (GPCR) research and understanding of the activation mechanism are important for the development of new drugs because more than $30 \%$ of drugs used today target GPCRs. ${ }^{1)}$ GPR56 belongs to the adhesion GPCR class, which has a long extracellular domain (ECD) and a cleaved site named the GPCR proteolytic site (GPS) upstream of transmembrane domain (TM). The cleavage occurs auto-catalytically and is necessary for maturation and activation of adhesion GPCRs. ${ }^{2}$ Although the cleaved ECD interacts with the TM, the physiological role of this interaction remains unclear. $^{3-5)}$

The ligands against most adhesion GPCRs are unknown. Therefore, research of this family has not progressed well. It has been reported that transglutaminase 2 (TG2), ${ }^{6)} \mathrm{CD} 81,{ }^{7}$ and collagen III ${ }^{8)}$ are the interactors of GPR56. Collagen III has been shown to inhibit the cell migration of neural progenitor cells. ${ }^{8)}$

Mutations of GPR56 have been found in the patients of bilateral frontoparietal polymicrogyria (BFPP), a genetic disorder affecting brain development. ${ }^{9)}$ According to our previous research, mouse GPR56 activates the G12/13 and Rho pathway, and this signaling inhibits the neural progenitor cell migration. ${ }^{10)}$ This result is coincident with the phenotype of the GPR56 knockout mouse, which causes neuronal cell overmigration. ${ }^{11)}$ Moreover, we found that the polyclonal antibody against GPR56 potentiated the Rho pathway and induced cell migration inhibition in mouse neural progenitor cells. ${ }^{10)}$ Recently, some reports indicated that GPR56 contributes to tumorigenesis. ${ }^{12-14)}$ Therefore, GPR56 is focused on as a target for anti-cancer drugs. In this research, we generated functional or non-functional monoclonal antibodies against human GPR56 and analyzed the action and signal transduction of GPR56 in human glioma U87-MG cells.

\section{MATERIALS AND METHODS}

Cell Culture and Transfection HEK293T cells and U87-MG cells were cultured in Dulbecco's modified Eagle's medium containing $10 \%$ fetal bovine serum, 100 units $/ \mathrm{mL}$ penicillin, and $100 \mu \mathrm{g} / \mathrm{mL}$ streptomycin at $37^{\circ} \mathrm{C}$ and $5 \% \mathrm{CO}_{2}$. Plasmid DNAs were transfected into HEK293T cells using the calcium phosphate method, and small interfering RNA (siRNA) was transfected into U87-MG cells using the Lipofectamine $^{\mathrm{TM}} 2000$ transfection reagent (Invitrogen, U.S.A.).

Recombinant Human GPR56ECD Protein Human GPR56ECD was produced using a baculovirus-Sf9 expression system and purified with ion exchange chromatography and affinity chromatography for His-tagged proteins as described previously. ${ }^{10)}$ Briefly, a pFast-Bac-1 vector containing GPR56ECD was introduced into DH10Bac. The recombinant bacmid was prepared to transfect into Sf9 cells. Recombinant baculovirus-infected Sf9 cells were cultured for $72 \mathrm{~h}$, and the supernatant of the culture medium was applied to SP-Sepharose FF column chromatography. An elution with $50 \mathrm{~mm}$ sodium phosphate buffer, $\mathrm{pH} 8.0$, containing $500 \mathrm{~mm}$ $\mathrm{NaCl}$, and $10 \mathrm{~mm}$ imidazole was collected and used for nickelNTA-agarose (Quiagen, U.S.A.). GPR56ECD was eluted with $400 \mathrm{~mm}$ imidazole and dialyzed with phosphate-buffered saline (PBS).

Monoclonal Antibodies BALB/c mice were immunized with five injections of $16.5 \mu \mathrm{g}$ human GPR56ECD (hGPR56ECD) recombinant protein into the footpad for 7 weeks. The popliteal lymph node cells were fused with mouse PAI myeloma cells by a polyethylene glycol method. Two hundred and fifty-six hybridomas were selected by enzyme-linked immunosorbent assay (ELISA) and expanded. An ELISA plate was prepared by coating with $1 \mu \mathrm{g} / \mathrm{mL}$ hGPR56ECD in a $50 \mathrm{~mm}$ carbonate buffer, $\mathrm{pH}$ 9.5. Monoclonal antibodies were purified by Protein-G Sepharose (GE Healthcare, U.S.A.) from 
conditioned media of hybridomas with a CD hybridoma medium (Invitrogen).

Migration Assay Four hundred thousand U87-MG cells were placed on an 8- $\mu \mathrm{m}$-pore-size Transwell (BD Biosciences, U.S.A.) together with antibodies and incubated for $4 \mathrm{~h}$. Cells on the top side of the filters were removed using a cotton bud, and the filters were fixed and stained with Diff-Quik (Sysmex, Japan). The number of stained cells on the bottom surface of the filters was counted.

Intracellular Calcium Assay Intracellular calcium mobilization was measured using the fluorescent $\mathrm{Ca}^{2+}$ indicator Fura-2 acetoxymethyl ester (Fura-2/AM) (Dojin Kagaku, Japan). Briefly, U87-MG cells were washed and detached in a suspension buffer (20 mM $N$-(2-hydroxyethyl)piperazine- $N^{\prime}-2$ ethanesulfonic acid-sodium hydroxide (HEPES-NaOH) $(\mathrm{pH}$ 7.5), $140 \mathrm{~mm} \mathrm{NaCl}, 5.4 \mathrm{~mm} \mathrm{KCl}, 1.8 \mathrm{~mm} \mathrm{CaCl}_{2}, 0.8 \mathrm{~mm} \mathrm{MgCl}_{2}$, and $5.6 \mathrm{~mm}$ glucose). The suspended cells were loaded with $2 \mu \mathrm{M}$ Fura-2/AM for $30 \mathrm{~min}$ at $30^{\circ} \mathrm{C}$ and then washed with a suspension buffer to remove the extracellular dye. For the fluorimetric measurement, $2 \times 10^{6}$ cells were placed into a cuvette in a thermostatically controlled cell holder at $37^{\circ} \mathrm{C}$ with continuous stirring. The cells were stimulated with $1 \mu \mathrm{M}$ endothelin-1 or $10 \mu \mathrm{g} / \mathrm{mL}$ anti-GPR56 antibodies. Fluorescence was monitored using an F-2000 fluorescence spectrophotometer (Hitachi, Japan) with emission at $510 \mathrm{~nm}$ after excitation at 340 and $380 \mathrm{~nm}$.

Immunoblotting Cells were lysed with a lysis buffer (20 mm HEPES-NaOH (pH 7.5), 0.5\% NP-40, $1 \mathrm{~mm}$ ethylene glycol bis(2-aminoethyl ether)- $N, N, N^{\prime}, N^{\prime}$-tetraacetic acid (EGTA), $3 \mathrm{~mm} \mathrm{MgCl}_{2}, 150 \mathrm{~mm} \mathrm{NaCl}, 1 \mathrm{~mm}$ phenylmethylsulfonyl fluoride (PMSF), and $1 \mu \mathrm{g} / \mathrm{mL}$ leupeptin). Samples in a Laemmli buffer were separated using sodium dodecyl sulfate (SDS)-polyacrylamide gels. The separated proteins were transferred to polyvinylidene difluoride membranes. After blocking for more than $30 \mathrm{~min}$ in $5 \%$ skim-milk PBST $\left(8 \mathrm{mM} \mathrm{Na}_{2} \mathrm{HPO}_{4}\right.$, $1.5 \mathrm{~mm} \mathrm{KH}_{2} \mathrm{PO}_{4}, 150 \mathrm{~mm} \mathrm{NaCl}, 0.1 \%$ Tween 20 ), membranes were probed for $1 \mathrm{~h}$ with primary antibodies in 5\% skim-milk PBST. The membranes were then washed three times with PBST and incubated with secondary antibodies coupled to horseradish peroxidase. Immunoblotting was visualized by using an enhanced chemiluminescence Western blotting detection kit (GE Healthcare).

Immunoprecipitation HEK293T cells were transfected with plasmids harboring human GPR56 cDNA. After $48 \mathrm{~h}$, cells were collected, and lysates were prepared with a lysis buffer. Cell lysates were used for immunoprecipitation with $1 \mu \mathrm{g}$ of anti-hGPR56ECD antibodies (18F2, 4C3, and 17CC) or control mouse immunoglobulin $\mathrm{G}(\mathrm{IgG})$ and protein-G Sepharose (GE Healthcare) for $1.5 \mathrm{~h}$ at $4^{\circ} \mathrm{C}$. Beads were washed with a lysis buffer six times, and immunoprecipitated proteins were eluted with a Laemmli buffer. Eluted proteins were not boiled; they were analyzed by immunoblotting with a GPR56 C-terminal (TM) antibody. This antibody was generated by injection of the mouse GPR56 C-terminal synthetic peptide (KNNSDSAKLPISSGSTSSSRI) conjugated to keyhole limpet hemocyanin (KLH) as an antigen into rabbits. ${ }^{11)}$ The antibody was affinity purified using the peptide-coupled NHS-activated Sepharose 4 Fast Flow (GE Healthcare).

\section{RESULTS}

Functional Antibodies against Human GPR56 Were Generated Previously, we found that the polyclonal rabbit antibody against mouse GPR56ECD acts as an agonistic ligand. ${ }^{10)}$ To obtain the functional monoclonal antibodies against human GPR56, we immunized mice with the recombinant protein of human GPR56ECD derived from baculovirus-infected Sf9 insect cells. We obtained 256 clones of hybridomas detected by ELISA screening. Among them, we selected 10 clones as the hybridomas producing the high-titer antibodies. Next, we tried to test the function of these monoclonal antibodies. It has been reported that human U87-MG glioma cells highly express GPR56. ${ }^{14)}$ We investigated the effect of antibodies on cell migration. Control mouse IgG has no inhibitory effect on the migration of human U87-MG cells (data not shown). This result coincided with the previous results indicating that rabbit control polyclonal antibody did not show any effect on the neuronal progenitor cell migration and SRE-mediated transcriptional activity. ${ }^{10)}$ Although several monoclonal antibodies against mouse GPR56ECD also had no effect on the U87-MG cell migration, three antibodies, 17CC, $4 \mathrm{C} 3$, and 11E9, strongly inhibited the motility of U87-MG cells (Fig. 1A). To confirm that the inhibition by these antibodies is mediated through GPR56, we performed the migration assay using a GPR56ECD recombinant protein (Fig. 1B). The recombinant protein completely blocked the inhibitory effect of 17CC and 4C3 on U87-MG cell migration. In addition, a knockdown experiment was performed with siRNA against human GPR56 (sihGPR56) (Figs. 1C, D). Anti-GPR56 antibody-induced inhibition was canceled by sihGPR56, and the knockdown of GPR56 did not affect cell migration. These results clearly indicate that these monoclonal antibodies have an inhibitory effect on glioma cell migration by binding to GPR56ECD.

Agonistic Antibodies Inhibit U87-MG Cell Migration via Gq and Rho Activation Previous research reported that CD81 forms a complex of human GPR56 with Gq, but it did not show the Gq-mediated cellular response induced by GPR 56. ${ }^{7}$ On the other hand, we showed that mouse GPR56 regulates cell migration via a G12/13 and Rho pathway. ${ }^{10)}$ Therefore, to investigate whether human GPR56 couples to Gq in U87-MG cells, we used YM-254890, a specific inhibitor of Gq. ${ }^{15)}$ Although YM-254890 alone did not affect cell migration, anti-GPR56 antibody-induced inhibition was canceled by treatment with YM-254890 (Fig. 2A). This result suggests that GPR56 in U87-MG cells is coupled with Gq, which is involved in cell migration inhibition.

In previous research of mouse neuronal progenitor cells, we indicated that Rho activation is involved in GPR56-induced action. ${ }^{10)}$ To examine whether the Rho pathway contributes to the inhibition of human glioma cell migration, we performed a migration assay using a Rho kinase inhibitor Y27632 (Fig. 3). Treatment with Y27632 canceled the inhibitory effect of agonistic antibodies, as with YM-254890. These results suggested that GPR56 may activate the Rho pathway via Gq in U87-MG cells.

Agonistic Antibodies Induce Calcium Response Next, we measured the intracellular calcium response induced by the antibodies (Fig. 2B). Endothelin-1, whose receptor is coupled with Gq, was used as a positive control. The functional 
A

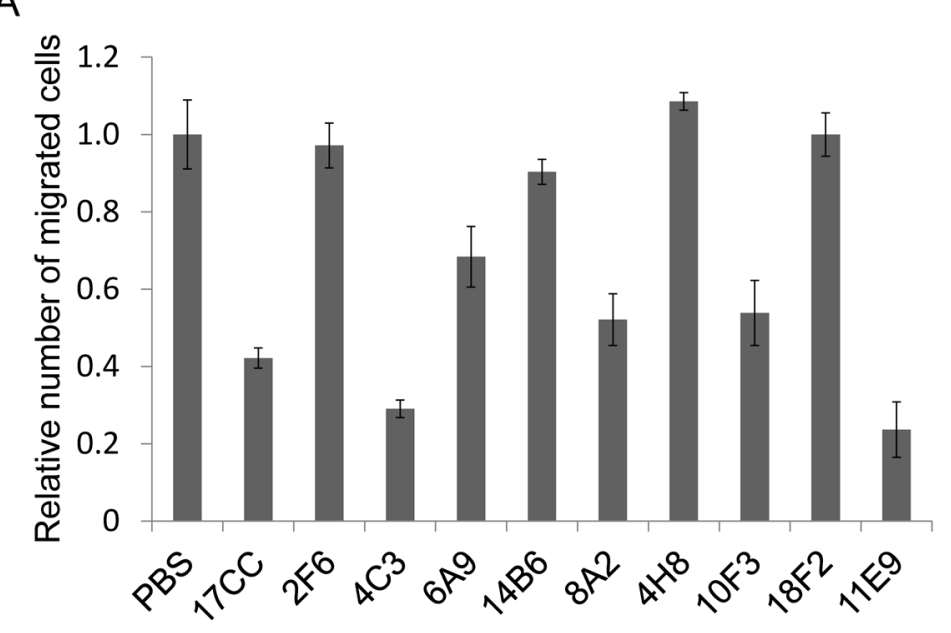

$\mathrm{B}$
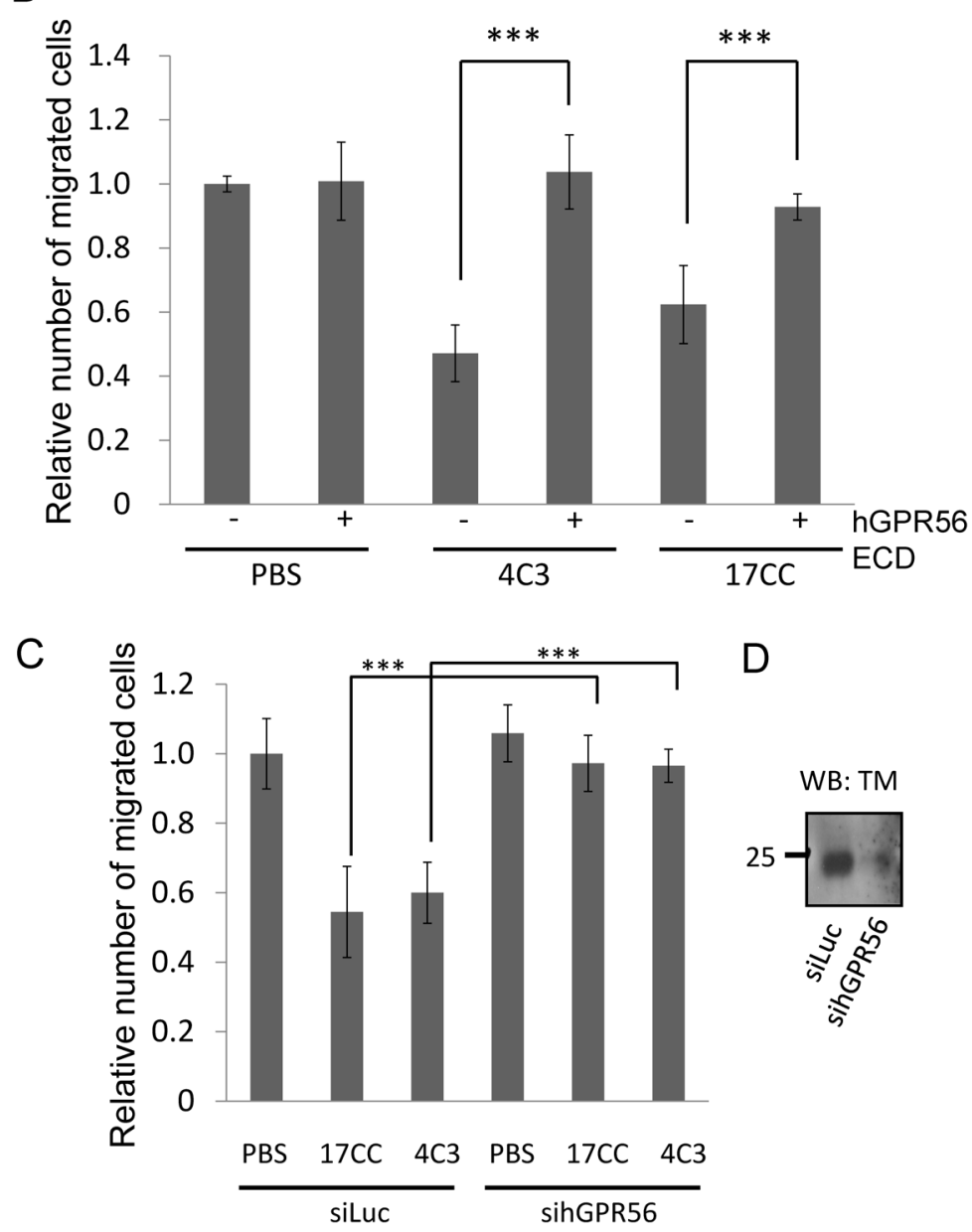

Fig. 1. Inhibitory Effects of Antibodies against Human GPR56ECD on U87-MG Cell Migration

(A) U87-MG cells in a Boyden chamber were treated with antibodies against GPR56ECD. The concentration of $17 \mathrm{CC}$ antibody was $10 \mu \mathrm{g} / \mathrm{mL}$, and others were $30 \mu \mathrm{g} /$ $\mathrm{mL}$. The numbers of migrated cells on the lower surface of the filter were counted $4 \mathrm{~h}$ after antibody treatments and were normalized to PBS treatment. The data from three experiments are the mean \pm standard deviation (S.D.). (B) The competitive effect of recombinant antigen protein. Ten micrograms/milliliter $17 \mathrm{CC}$ antibody or $30 \mu \mathrm{g} /$ $\mathrm{mL} 4 \mathrm{C} 3$ antibody was pre-incubated with or without $10 \mu \mathrm{g} / \mathrm{mL}$ hGPR56ECD recombinant protein and used for a cell migration assay. The data from three experiments are the mean \pm S.D. ${ }^{* *} p<0.01$, Student's $t$-test. (C) The effect of GPR56 knockdown on the antibody-induced inhibition of cell migration. The migration assay with a 17 CC or $4 \mathrm{C} 3$ antibody was performed $2 \mathrm{~d}$ after transfection of siRNA against luciferase (siLuc) or human GPR56 (sihGPR56). The data from three experiments are the mean \pm S.D. $* * * p<0.01$, Student's $t$-test. (D) Immunoblotting of GPR56 using the GPR56 C-terminal (TM) antibody. The expression of endogenous GPR56 in U87-MG cells was decreased by sihGPR56.

antibodies, 4C3, 11E9, and 17CC, induced a calcium response, whereas the non-functional antibodies, $2 \mathrm{~F} 6$ and $18 \mathrm{~F} 2$, did not show any calcium response as same as control mouse IgG.
Moreover, these calcium responses were canceled by treatment with YM-254890. These results indicated that the functional antibodies against hGPR56 induced Gq activation in human 
A

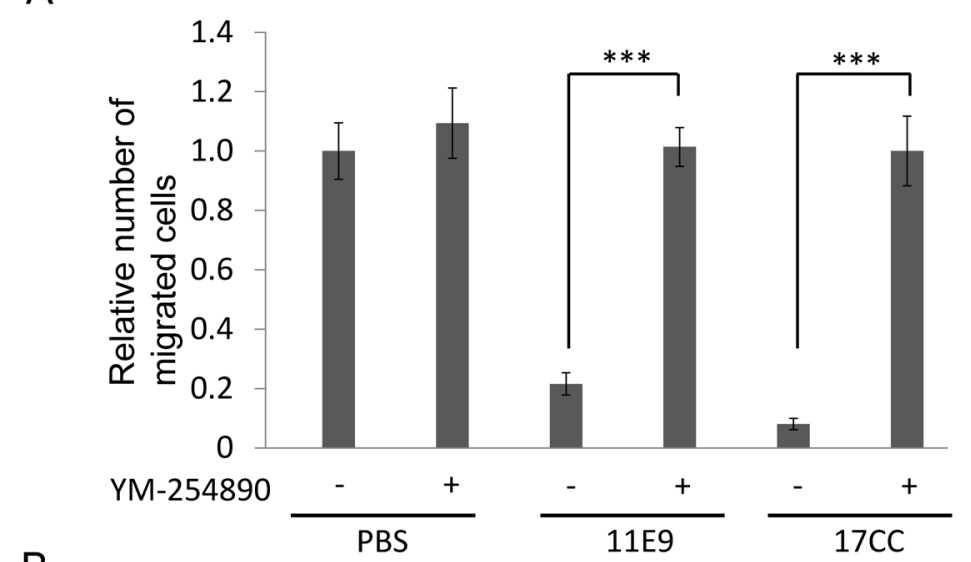

B
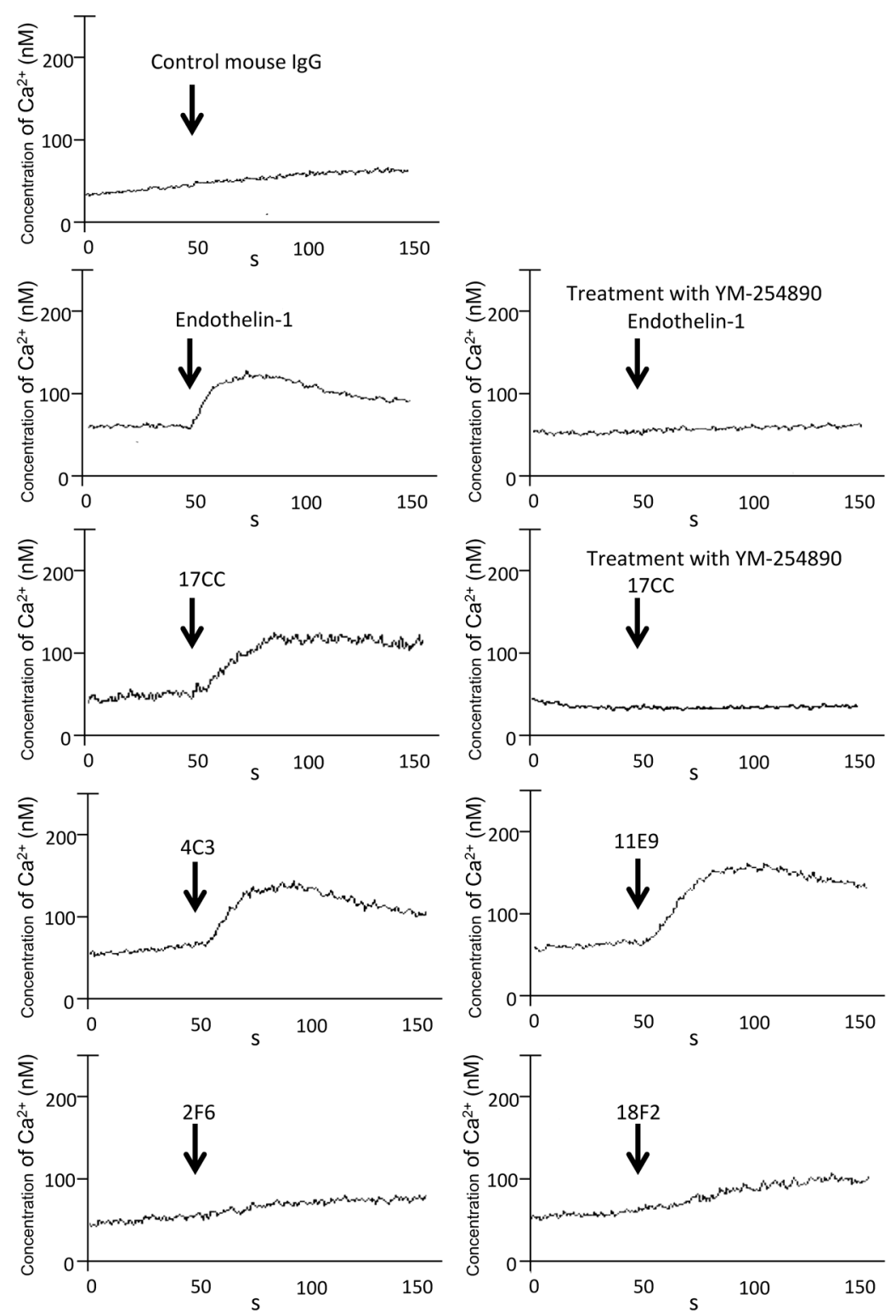

Fig. 2. Agonistic Antibodies Inhibited U87-MG Cell Migration via Gq

(A) The Gq inhibitor YM-254890 attenuated the inhibitory effect of agonistic antibodies on the migration. One micromolar YM-254890 was used for a U87-MG cell migration assay. The data from three experiments are the mean \pm S.D. $* * * p<0.01$, Student's $t$-test. (B) Agonistic antibodies induced Gq-mediated Ca ${ }^{2+}$ responses. Calcium response by antibodies was measured in U87-MG cells using fluorometric $\mathrm{Ca}^{2+}$ indicator Fura-2. Two micromolar endothelin-1 was used as the positive control. The concentration of each antibody was $10 \mu \mathrm{g} / \mathrm{mL}$. One micromolar YM- 254890 was added just before $\mathrm{Ca}^{2+}$ measurement. Data are representative of at least three separate experiments. 


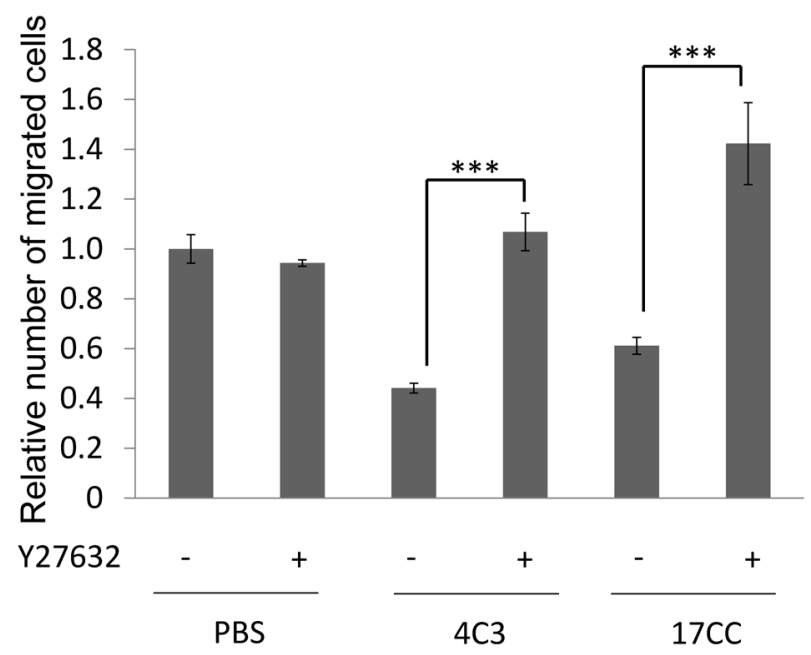

Fig. 3. Rho Kinase Inhibitor Y27632 Canceled the Effect of Agonistic Antibodies on the Migration

One micromolar Y27632 was added to the cell culture medium. S.D. of the mean is shown as a bar. $(n=3) * * * p<0.01$, Student's $t$-test.

A

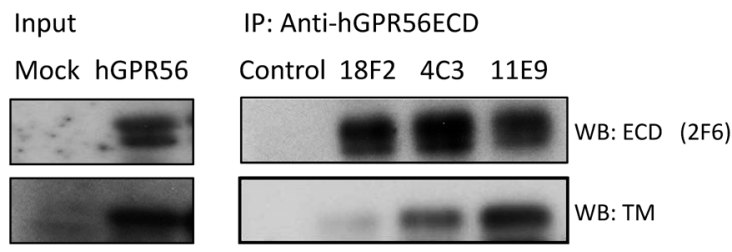

B

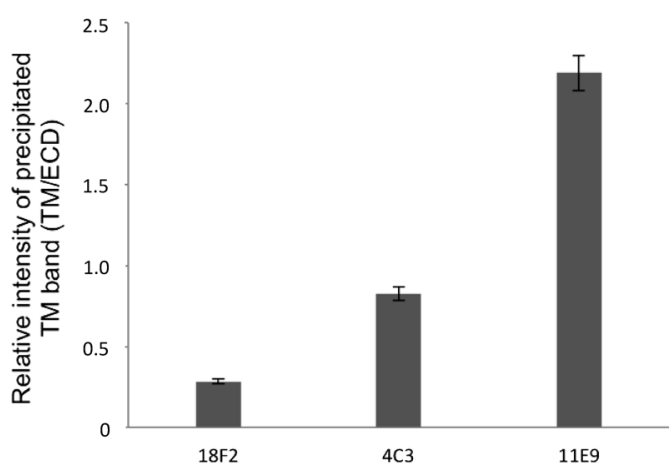

Fig. 4. Interaction between Human GPR56ECD and TM

(A) HEK293T cells were transfected with human GPR56 (hGPR56). GPR56 in cell lysate shown as input hGPR56 of left photograph was immunoprecipitated with the antibodies against hGPR56ECD (18F2, 4C3, and 11E9). Mouse IgG (Control) was used as a negative control. The precipitated ECD and co-precipitated transmembrane (TM) domains were detected by the antibodies against hGPR56ECD (2F6) and hGPR56-TM domains, respectively. (B) Quantitative analysis of interac tion between human GPR56ECD and TM. Vertical axis means the precipitated TM amount with anti-hGPR56ECD antibodies. Three independent experiments were performed. S.D. of the mean is shown as a bar

glioma U89-MG cells.

Agonistic Antibodies Promote Interaction between ECD and TM Adhesion GPCRs have a long ECD containing a GPS domain, which was cleaved from the TM. It was reported that the GPR56ECD may have an inhibitory effect on GPR56 signaling. ${ }^{16)}$ Therefore, there was one possibility that agonistic antibodies weaken the interaction between the ECD and TM. To investigate this possibility, we performed immunoprecipitation experiments using agonistic or non-functional antibodies. On the contrary, agonistic antibodies, 4C3 and 11E9, markedly potentiated the interaction between the ECD and TM (Fig. 4). It is suggested that an agonistic antibody induces the conformation change of GPR56ECD to promote interaction with the TM.

\section{DISCUSSION}

Orphan GPCR research has not progressed well, because ligand screening and hunting is time-consuming and laborious. Some agonistic antibodies against GPCRs have been reported. The antibody against the $\beta$-adrenergic receptor increased the stabilization of the receptor activating form, ${ }^{17)}$ and adrenergic or cholinergic autoantibody activity may be present in the sera of patients with chronic heart failure. ${ }^{18)}$ It is well known that the autoantibody against the thyroid-stimulating hormone receptor (TSHR) causes Basedow's disease. ${ }^{19)}$ In a previous study, we showed that the rabbit polyclonal antibody against mouse GPR56ECD inhibited the migration of neuronal progenitor cells via a G12/13 and Rho pathway. ${ }^{10)}$ In this study, the monoclonal antibodies against human GPR56 can act as an agonist to induce cellular responses. Taken together with previous experiments, the monoclonal antibodies against GPCRs can be useful tools for investigating the function of orphan GPCRs.

In this research using the functional antibodies, we first showed direct evidence that human GPR56 regulates cell migration via Gq. It was reported that human GPR56 forms a complex with Gq in the presence of CD81. ${ }^{7)}$ However, in that report, there was no evidence that human GPR56 activates Gq. ${ }^{7)}$ We generated monoclonal antibodies against human GPR56, and we obtained agonistic antibodies 4C3, 11E9, and 17CC. These antibodies induced the calcium response and inhibited U87-MG cell migration, and a Gq-specific inhibitor, YM-254890, canceled these effects of antibodies. Moreover, a Rho kinase inhibitor, Y27632, also canceled the inhibitory effect of antibodies on the migration. Generally, it is well known that $\mathrm{Gq}$ induces a calcium response via phospholipase $\mathrm{C} \beta$ activation. Recently, it was found that Gq interacts with p63RhoGEF and activates Rho and the Rho kinase. ${ }^{20)}$ Our results indicated that human GPR56 couples with Gq, and GPR56 signaling regulates cell migration via the Rho kinase in U87-MG cells. The result that Gq coupled with GPR56 in U87-MG cells is inconsistent with our previous result in mouse neuronal progenitor cells. It is known that some GPCRs are able to couple with distinct $\mathrm{G}$ proteins. For example, the S1P receptor couples with both G12/13 and Gq and induces inhibition of migration in vascular smooth muscles in a manner dependent on Rho. ${ }^{21)}$ GPR56 also might be coupled with $\mathrm{Gq}$ and G12/13 in U87-MG cells. It is possible that the coupling of the G protein with GPR56 may vary according to cell types and/or dependent on the presence of a coupling protein, such as CD81. However, in human glioma U87-MG cells and mouse neuronal progenitor cells, it is common for GPR56 signaling to inhibit cell migration via the Rho pathway. Activated Rho promotes the actin stress fiber formation and the cell attachment. ${ }^{22)}$ It was reported that the Rho and/ or Rho kinase are involved in the cell migration inhibition of macrophage, ${ }^{23)}$ B-cell lymphoma ${ }^{24)}$ and vascular smooth muscle. ${ }^{21)}$ The cell migration is controlled by the accurate spatiotemporal regulation of the actin cytoskeleton in the balance of Rho and Rac activities. 
The physiological significance and action of the ECD of the adhesion GPCR on receptor activation are not clear. It was thought that the ECD interacts with the 7 transmembrane at the cell surface after cleavage. In the case of TSHR, which is a member of the rhodopsin family of GPCR, it has been suggested that the ECD inhibits TM signaling. ${ }^{19)}$ Recently, the study using a deletion mutant suggested that the ECD of GPR56 might inhibit TM signaling. ${ }^{16)}$ In the recent report, the ECD of Latrophilin 1, which is also a member of the adhesion GPCR class, can move freely at the cell surface and influence other GPCR signaling. ${ }^{25)}$ In our immunoprecipitation experiment using agonistic and non-functional antibodies, the TM domain was preferentially precipitated by agonistic antibodies 4C3 and 11E9, as compared to the non-functional antibody $18 \mathrm{~F} 2$. This result suggested that agonistic antibody might enhance the interaction between the ECD and TM more tightly to stimulate intracellular signaling. It was reported that an ECD-deleted mutant of GPR56 shows higher activity. ${ }^{16)}$ However, that report did not show direct evidence that the ECD inhibits GPCR signaling. Therefore, we first showed the agonist-dependent interaction of the ECD and TM domains by biochemical analysis. Epitope mapping analysis using several monoclonal antibodies and deleted- or mutated-GPR56 is in progress. It will be very interesting to determine the complex structure of the monoclonal antibody and GPR56ECD by $\mathrm{X}$-ray crystal structure analysis.

Classically, one GPCR is activated after ligand binding and induces a guanosine 5'-diphosphate/guanosine 5'-triphosphate (GDP/GTP) exchange of G $\alpha$. Recently, however, some research indicates that the GPCR activation mechanism is more complicated, including GPCR heterodimerization and the interaction of other lipid proteins. ${ }^{26)}$ Our research shows the possibility that an antibody is a very useful tool for orphan receptor research to analyze the function and activation mechanism. It means that the antibody is not only the substitute for the real ligand but also makes it possible to discover the activation mechanism. Furthermore, functional antibodies are invaluable tools for GPCR research and should open a new avenue for therapeutic treatment of tumors.

Acknowledgments This work was supported by Grantsin-Aid for Scientific Research from the Ministry of Education, Culture, Sports, Science and Technology of Japan (Grant numbers: 24590113, 25121724, and 25293013) and by a Grant from the Takeda Science Foundation.

Conflict of Interest The authors declare no conflict of interest.

\section{REFERENCES}

1) Drews J. Drug discovery: a historical perspective. Science, 287, 1960-1964 (2000).

2) Lin HH, Chang GW, Davies JQ, Stacey M, Harris J, Gordon S. Autocatalytic cleavage of the EMR2 receptor occurs at a conserved $\mathrm{G}$ protein-coupled receptor proteolytic site motif. J. Biol. Chem., 279, 31823-31832 (2004).

3) Gray JX, Haino M, Roth MJ, Maguire JE, Jensen PN, Yarme A, Stetler-Stevenson MA, Siebenlist U, Kelly K. CD97 is a processed, seven-transmembrane, heterodimeric receptor associated with inflammation. J. Immunol., 157, 5438-5447 (1996).

4) Krasnoperov VG, Bittner MA, Beavis R, Kuang Y, Salnikow KV,
Chepurny OG, Little AR, Plotnikov AN, Wu D, Holz RW, Petrenko AG. Alpha-latrotoxin stimulates exocytosis by the interaction with a neuronal G-protein-coupled receptor. Neuron, 18, 925-937 (1997).

5) Abe J, Fukuzawa T, Hirose S. Cleavage of Ig-Hepta at a "SER" module and at a conserved $\mathrm{G}$ protein-coupled receptor proteolytic site. J. Biol. Chem., 277, 23391-23398 (2002).

6) $\mathrm{Xu} \mathrm{L}$, Hynes RO. GPR56 and TG2: possible roles in suppression of tumor growth by the microenvironment. Cell Cycle, 6, 160-165 (2007).

7) Little KD, Hemler ME, Stipp CS. Dynamic regulation of a GPCRtetraspanin-G protein complex on intact cells: central role of CD81 in facilitating GPR56-G $\alpha \mathrm{q} / 11$ association. Mol. Biol. Cell, 15, 2375-2387 (2004).

8) Luo R, Jeong SJ, Jin Z, Strokes N, Li S, Piao X. G protein-coupled receptor 56 and collagen III, a receptor-ligand pair, regulates cortical development and lamination. Proc. Natl. Acad. Sci. U.S.A., 108, 12925-12930 (2011).

9) Piao X, Hill RS, Bodell A, Chang BS, Basel-Vanagaite L, Straussberg R, Dobyns WB, Qasrawi B, Winter RM, Innes AM, Voit T, Ross ME, Michaud JL, Descarie JC, Barkovich AJ, Walsh CA. G protein-coupled receptor-dependent development of human frontal cortex. Science, 303, 2033-2036 (2004).

10) Iguchi T, Sakata K, Yoshizaki K, Tago K, Mizuno N, Itoh H. Orphan $\mathrm{G}$ protein-coupled receptor GPR56 regulates neural progenitor cell migration via a $\mathrm{G}$ alpha $12 / 13$ and Rho pathway. J. Biol. Chem., 283, 14469-14478 (2008).

11) Li S, Jin Z, Koirala S, Bu L, Xu L, Hynes RO, Walsh CA, Corfas G, Piao X. GPR56 regulates pial basement membrane integrity and cortical lamination. J. Neurosci., 28, 5817-5826 (2008).

12) $\mathrm{Xu} \mathrm{L,} \mathrm{Begum} \mathrm{S,} \mathrm{Hearn} \mathrm{JD,} \mathrm{Hynes} \mathrm{RO.} \mathrm{GPR56,} \mathrm{an} \mathrm{atypical} \mathrm{G}$ protein-coupled receptor, binds tissue transglutaminase, TG2, and inhibits melanoma tumor growth and metastasis. Proc. Natl. Acad. Sci. U.S.A., 103, 9023-9028 (2006).

13) Ke N, Sundaram R, Liu G, Chionis J, Fan W, Rogers C, Awad T, Grifman M, Yu D, Wong-Staal F, Li QX. Orphan G protein-coupled receptor GPR56 plays a role in cell transformation and tumorigenesis involving the cell adhesion pathway. Mol. Cancer Ther., 6, 1840-1850 (2007).

14) Shashidhar S, Lorente G, Nagavarapu U, Nelson A, Kuo J, Cummins J, Nikolich K, Urfer R, Foehr ED. GPR56 is a GPCR that is overexpressed in gliomas and functions in tumor cell adhesion. Oncogene, 24, 1673-1682 (2005).

15) Nishimura A, Kitano K, Takasaki J, Taniguchi M, Mizuno N, Tago $\mathrm{K}$, Hakoshima T, Itoh H. Structural basis for the specific inhibition of heterotrimeric $\mathrm{Gq}$ protein by a small molecule. Proc. Natl. Acad. Sci. U.S.A., 107, 13666-13671 (2010).

16) Paavola KJ, Stephenson JR, Ritter SL, Alter SP, Hall RA. The N terminus of the adhesion $\mathrm{G}$ protein-coupled receptor GPR56 controls receptor signaling activity. J. Biol. Chem., 286, 28914-28921 (2011).

17) Lebesgue D, Wallukat G, Mijares A, Granier C, Argibay J, Hoebeke J. An agonist-like monoclonal antibody against the human $\beta 2$ adrenoceptor. Eur. J. Pharmacol., 348, 123-133 (1998).

18) Herda LR, Felix SB, Boege F. Drug-like actions of autoantibodies against receptors of the autonomous nervous system and their impact on human heart function. Br. J. Pharmacol., 166, 847-857 (2012).

19) Smith BR, Sanders J, Furmaniak J. TSH receptor antibodies. Thyroid, 17, 923-938 (2007).

20) Lutz S, Freichel-Blomquist A, Yang Y, Rumenapp U, Jakobs KH, Schmidt M, Wieland T. The guanine nucleotide exchange factor p63RhoGEF, a specific link between Gq/11 coupled receptor signaling and RhoA. J. Biol. Chem., 280, 11134-11139 (2005).

21) Takashima S, Sugimoto N, Takuwa N, Okamoto Y, Yoshioka K, Takamura M, Takata S, Kaneko S, Takuwa Y. G12/13 and Gq mediate S1P2-induced inhibition of Rac and migration in vascular smooth muscle in a manner dependent on Rho but not Rho kinase. 
Cardiovasc. Res., 79, 689-697 (2008).

22) Hall A. Rho family GTPases. Biochem. Soc. Trans., 40, 1378-1382 (2012).

23) Gui P, Labrousse A, Van Goethem E, Besson A, MaridonneauParini I, LeCabec V. Rho/ROCK pathway inhibition by the CDK inhibitor p27(kip1) participates in the onset of macrophage 3Dmesenchymal migration. J. Cell Sci., 127, 4009-4023 (2014).

24) Muppidi JR, Schmitz R, Green JA, Xiao W, Larsen AB, Braun SE, An J, Xu Y, Rosenwald A, Ott G, Gascoyne RD, Rimsza LM, Campo E, Jaffe ES, Delabie J, Smeland EB, Braziel RM, Tubbs
RR, Cook JR, Weisenburger DD, Chan WC, Vaidehi N, Staudt LM, Cyster JG. Loss of signaling via $\mathrm{G} \alpha 13$ in germinal centre B-cellderived lymphoma. Nature, 516, 254-258 (2014).

25) Volynski KE, Silva JP, Lelianova VG, Rahman MA, Hopkins C, Ushkaryov YA. Latrophilin fragments behave as independent proteins that associate and signal on binding of $\mathrm{LTX}^{\mathrm{N} 4 \mathrm{C}}$. EMBO J., 23, 4423-4433 (2004).

26) Latek D, Modzelewska A, Trzaskowski B, Palczewski K, Filipek S. $\mathrm{G}$ protein-coupled receptors-recent advances. Acta Biochim. Pol., 59, 515-529 (2012). 